\title{
Survival and Physical Growth in Infancy and Early Childhood
}

Study of Birth Weight and Gestational Age in a Guatemalan Indian Village.

Leonardo J. Mata, ScD; Juan J. Urrutia, MD; Richard A. Kronmal, PhD; Claire Joplin, MS 


\title{
Survival and Physical Growth in Infancy and Early Childhood
}

\author{
Study of Birth Weight and Gestational Age \\ in a Guatemalan Indian Villag-
}

Leonardo J. Mata. SeD; Juan J. Urrutia. MD; Richard A. Kronmal. PhD; Claire Joplin. MS

\begin{abstract}
$M^{\text {an }}$ any factors contribute independently or jointly to the cause and pathogenesis of low birth weight. Attempts to identify these factors in a given population, however, are usually unsuccessful, and conclusions are equivocal. Among the variables related to fetal growth, socioeconomic status and size of the mother consistently show positive correlations. Thus, incidence of low birth weight. defined as less than 2,501 gm (5.5 Ib),' is lowest in the nations with the highest standard of living.' Although the United States is among the most developed nations, its incidence of low birth weight is higher than that of some European countries,' primarily because of the high incidence of low

From the Division of Environmental Biology. Institute of Nutrition of Central America and Panama. Guatemala City (Drs. Mata and Urrutia); and the departments of epidemiology and international health (Dr. Mata) and biostatistics (Dr. Kl'Onmai and Ms. Joplin). University of Washington, Seattle. Dr. Mata is now with the University of Costa Rica. Guadalupe.

Reprint requests to University of Costa Rica. Guadalupe. Costa Rica (Dr. Mata).
\end{abstract}

birth weight among its population groups of low socioeconomic class.

The problem is more serious in developing nations. but it is extremely difficult to assess there because of inadequacy or lack of statistical data. Data on birth weight in these countries are usually derived from hospital records that, aside from their inaccuracy, are not representative of the rural and peripheral urban population. Nevertheless, even such lim- ited reports from Latin America, Asia, and Africa". indicate low birth weight rates ranging from $16 \%$ to $26 \%$.

The magnitude of the problem of low birth weight can only be assessed by prospective observation of communities that are representative of larger areas or regions. One such study has been underway since 1963 in a typical Guatemalan Indian vilJage, Santa Maria Cauque. When the 
Table 2.-Weight and Height of Cohorts Born in Different Years by Age.

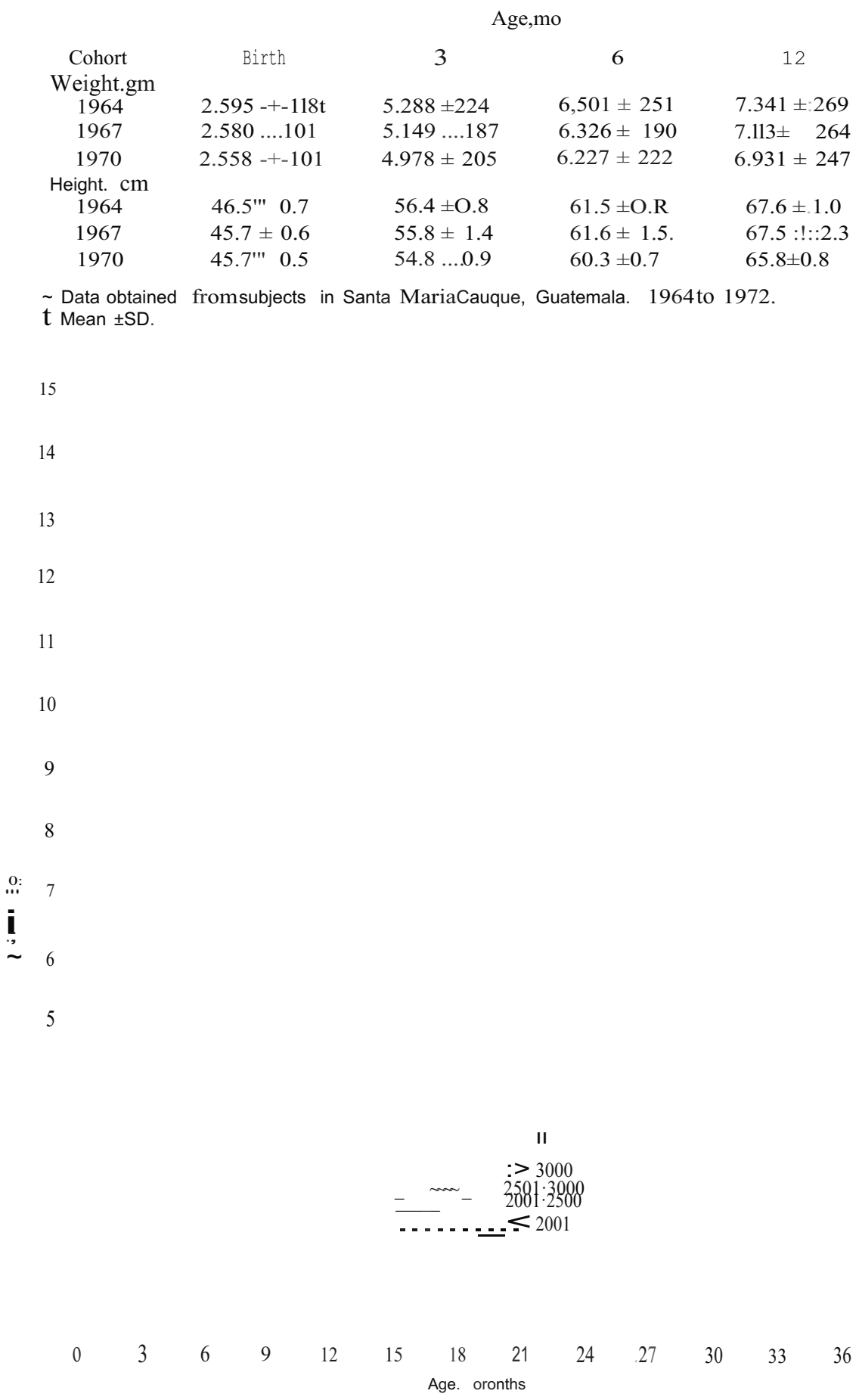

Fig I.-Weight curves (means \pm 2 SE) of cohorts of children defined by birth weight. Santa Maria Cauque. Guatemala, 1964 to 1972. in comparison with INeAP standard." Numbers in curves denote children measured.

study began, this community, near Guatemala City at an altitude of 1,890 meters $(6,200 \mathrm{ft})$, had a popuiation of 1,071. By 1971, when ohservations reported here were com- pleted, it had grown to 1,370 people, and it has heen growing at a rate of $3 \%$ per year with minimal migration.':v The hirth rate has heen approximately 50 per 1,000 population, with an infant mortality of about 90 per 1,000 livebirths. Deliveries take place at home according to tradition and custom. Breast feeding is' begun shortly altei birth; and the total lactation ::period is: one. to four' years. Chronic. protein-calorie malnutrition and' a: high rate of infection are prevalentin people of all ages.':'

\section{SUBJECTSAND METHODS}

Early in 1963, a health center, staffed by a team of health workers, established a firm association with villagers that permitted observations on virtually the whole population. The center provides care and serves as a base of operations. Services consist of treatment of illnesses and injuries. However, immunization programs were deficient and no large-scale nutritional or health intervention was implemented during the period of observation (1963 to 1972).

The key factor responsible for the completeness and high accuracy qf the collected data was an early acquaintance with the village authorities, leaders, women, and folk midwives, Deliveries were reported when they took place. Auxiliary public health nurses, posted in the' village around the dock [including weekends), visited the homes within one hour of an infant's birth, measuring the newborn and collecting pertinent information about the mother and the infant and their immediate environment

There were 465 deliveries during the study period, resulting in 460 singletons and ten twins. Among the singletons, 446 were born alive: birth weight was obtained on $430 \mathrm{f96}$,)?)and gestational age on 416 (9a"O.All infants remained under observation and were weighed and measured periodieally.':"

\section{RESULTS}

There was a remarkable constancy in the pattern of fetal growth, infant mortality, and postnatal growth during the study period. The mean and standard deviation of birth weight were similar during the individual years of the study, as was the incidence of low-birth-weight infants (Table 1). Likewise, the mean weight and height at various ages, exhibited by the yearly cohorts, were quite stable (Table 2). Although some environmental and social characteristics changed during the study period (for example, the average area of land for 
Fig 2.-Mean head circumference curves of cohorts of children defined by birth weight. Santa Maria CauQue. Guatemala. 1964 to 1972. Numbers in curves denote children measured.

cultivation per family decreased by $20 \%$, more men became landless laborers, the water supply was improved, electric current became available, and there was a slight decrease in the illiteracy tate), such changes apparently did not result in alterations of behavior of important biological variables used to measure fetal and postnatal growth. This constancy of biological measurements permits the following analysis and interpretations.

\section{Survival}

A direct correlation between gestational age and survival was also noted. This association, however, was not as clear-cut, although products of gestation of less than :i7 weeks had a higher mortality than term newborns (Table 3). Survival of term infants was almost always associated with large birth weight. Since, under field conditions, birth weight can he determined better than gestational age, it becomes a good predictor of survival in the neonatal and postneonatal period.

The relationship of fetal maturity (defined by the combination of birth weight and gestational age) to survival is described elsewhere." Preterm infants died more often than was expected. The small-for-date infants born at term had a high mortality in the first two years of life. Term infants adequate for gestational age fared the best.

\section{Postnatal Growth}

All of the 430 singletons with known birth weight and all of the 416 with known gestational age were observed prospectively. Seven children were lost to follow-up because of migration. Other attrition in numbers was due to the fact that the data are

Fig 3.-Mean weight curves of cohorts of children defined by gestational age, Santa Maria Cauque. Guatemala. 1964 to 1972 . it' comparison with INeAP standard. "' Num. bers in curves denote children measured.

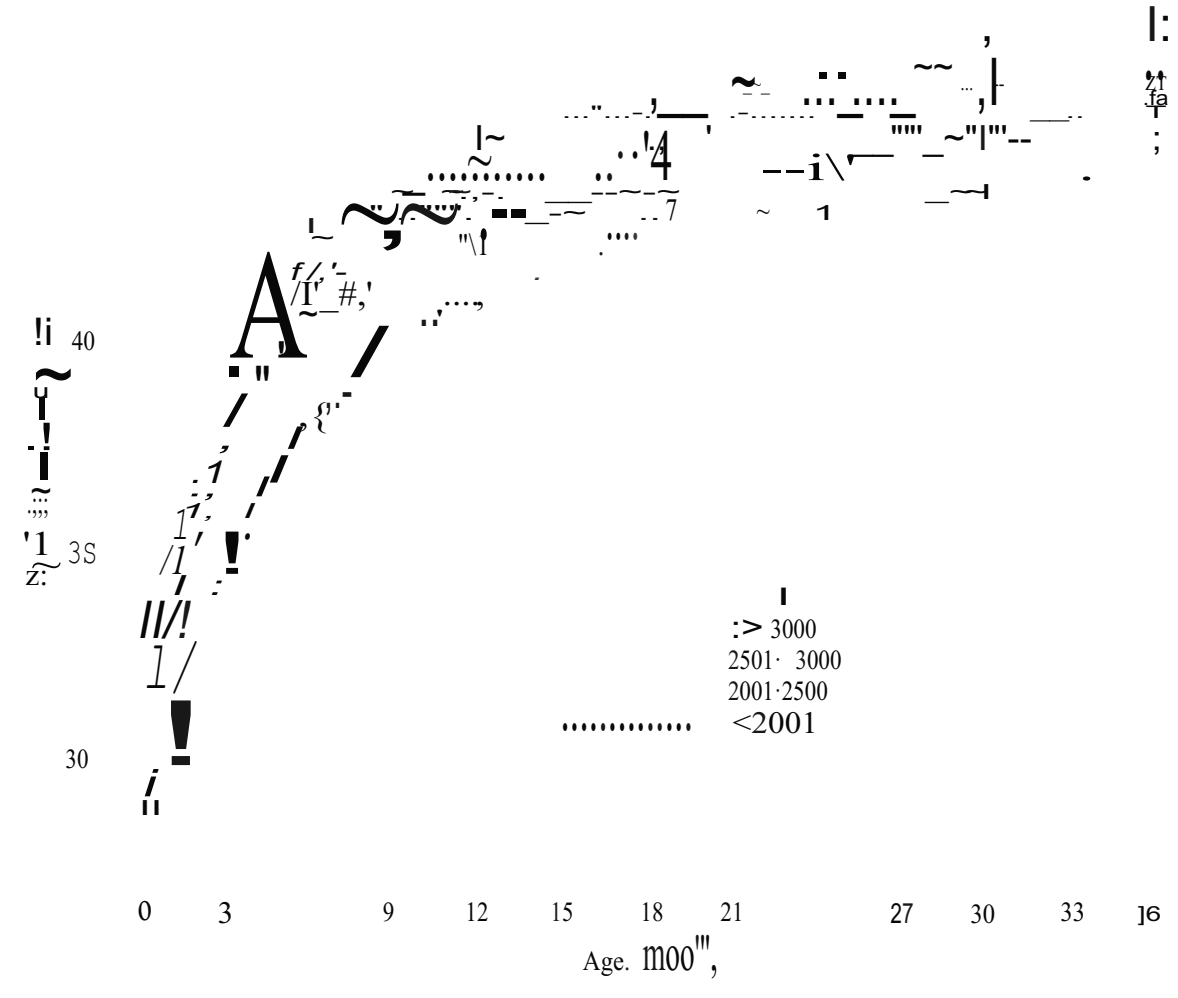

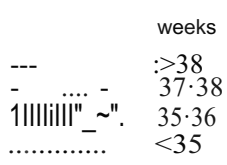

0
3
6
12
15
$18 \quad 21$
$\begin{array}{llll}27 & 30 & 33 & 36\end{array}$ 
Table 3.-Infant Deaths in Relation to Birth Weight-

\begin{tabular}{|c|c|c|c|}
\hline & & \multicolumn{2}{|c|}{ Ap } \\
\hline $\begin{array}{l}\text { Birn } \\
\text { Wellht. }\end{array}$ & No. $\mathrm{C}$ & 29 & 29 0.ys- \\
\hline am & Infar & 0.1. & $5 \mathrm{~m}$ \\
\hline $\begin{array}{c}<1,501 \\
1.501-1.75\end{array}$ & $\begin{array}{r}5 \\
11\end{array}$ & $\begin{array}{l}3(600) \mathrm{t} \\
2(182)\end{array}$ & $\begin{array}{l}1(200) \\
3(273)\end{array}$ \\
\hline $1.751-2.00$ & 17 & $4(235)$ & $4(235)$ \\
\hline $1 \cdot 2.25$ & 47 & $2(43)$ & $2(43)$ \\
\hline $2.251-2.500$ & 99 & $3(30)$ & \\
\hline & 0125 & $2(16)$ & $3(24)$ \\
\hline 2.751 .3 .000 & 0: 82 & 0 & 2.(24) \\
\hline & 32 & O & 0 \\
\hline & 11 & 0 & 0 \\
\hline$>3.500$ & 1 & 0 & \\
\hline Cotal & 430 & $16(37)$ & $15(35)$ \\
\hline
\end{tabular}

Data obtained from 430 singleton infants in Santa Maria cauque, Guata " 1964 to 1973.

$t$ Deaths. and in parentheses. rate per 1.000 live births of that birth weight category.

based on eouorts wuose numbers become fewer. with progressive age, and to death. which was more frequent during the first two years of life (L, J. Mata, SeD, et al, unpublished data).

Weight curves were determined for children within categories of birth weight, computing the means $( \pm 2$ SE) of weight values at three-month intervals (Fig 1). When a measurement was not available, the closest value within approximately two weeks was used. It is evident that the proportionate differences in weight observed at birth are maintained during the first years of life. Unpublished observations of the 1964 and 1965 cohorts indicate that children tend to remain within their birth

". weight categories during the first eight years of life. A similar tendency is noted for head circumference (Fig 2) and height, but less so for chest circumference. Measurement of the last carries a much greater risk of inherent error:

For all vananles, the lowest curves cor. >ond to the very small infants (less than $2.001 \mathrm{gm}$ [4.4 Ib]) who were preterm by gestational age. The next lowest curves represent children with birth weights of 2,001 to 2,500 gm, most of whom had 37 or more weeks of gestation. A few of these were preterm by gestational age and as a group behaved differently from those small for gestational age in that their growth curve was very close to that of full-term infants with birth weights of 2,501 to 3,000 gm (6.6 Ib)." Infants with birth weights above 2,500 gm exhibited different growth patterns (Fig 1 and 2) if they were subdivided into two birth weight groups

Weight curves as a function of gestational age tended to show only two distinct groups, "the preterm and the term infants (Fig 3). The same applies to height and head and chest circumferences. Head circumference correlated well with gestational age during the first 15 months of life; thereafter, differences were less noticeable. It should be stressed that head circumference and gestational age correlated well during the period of head growth, and particularly in the first months of life.

The growth pattern as a function of fetal maturity (defined by birth weight and gestational age) is described elsewhere." Preterm infants with very low birth weights had the worst growth curves. Small-for-date infants born at term were next, and term infants adequate for gestational age grew best.

\section{COMMENT}

In the region from which these data were derived, there is considerable biological stability in host measurements. Whatever changes were detected in certain host and environmental variables in the eightyear span did not appear to influence biological measurements such as birth weight, infant mortality, and physical growth. Among three dozen variables relating to ethnic composition, family size, family organization. literacy and schooling, land andhome ownership, type of agricultural crops, quality of housing and environmental sanitation analyzed between 1959 and 1971 at four-year intervals, only a few showed substantial change. A similar stability has been noted about food habits and prevalence of infection.

Whereas stable preindustrial societies are known to exist,'; certain evolutionary changes are detected even under conditions of isolation. Guatemalan Indian and non-Indian villages show considerable proclivity toward change at the moment, but the remarkable constancy of certain host and environmental factors offers a unique opportunity for observing associations between antenatal and postnatal events, as illustrated above.

An extremely high incidence of low birth weight occurs in this village.":" Studies from Latin America; Africa, and Asia-:" indicate the universality of the problem, which is not yet recognized because adequate statistics are generally lacking.

In the Indian village, most neonatal and postneonatal infant deaths occurred among low-birth-weight infants, supporting the classical concept of the relationship between low birth weight and poor survival established in urban industrial populations. 1.1 A A well-trained pediatrician and two public health auxiliary nurses closely attended most ill village infants, administering antibiotics, hydration, and advice whenever necessary. These measures decreased the infant mortality by, $40 \%$ from the preexisted level (J. L. Mata, SeD, et al, unpublished data), but. failed to lower it below 90 per 1,000 live births.

The association between low birth weight and survival was so striking that infant mortality stands out as an indicator of fetal growth and maternal health. On the basis of the data presented, it can be assumed that an infant mortality Of 100 'per' 1,000 in similar regions where infants are breast fed indicates a $30 \%$ to $40 \%$ incidence of low birth weight, providing tetanus neonatorum is not a problem in the area. This concept, however, cannot be generalized to all situations. For example, a high infant mortality may occur despite a low incidence of low birth weight if infants are improperly weaned at an early age, as presently occurs in large urban centers of developing nations. An international investigation of childhood mortality" has shown that the interaction of poverty, low birth weight, improper weaning, and infectious disease accounts for most premature deaths throughout large urban areas of Latin America.

Observations reported here show that fetal growth is correlated with postnatal physical growth. Infants 
born with deficient weight (or preterm) had a tendency to remain in the lower growth tracks, whether the variable measured was weight, height, or head and chest circumferences. This applied throughout the length of the study, ie, seven years. Differences of weight became accentuated with time; those of head circumference were greater during the first 15 months of life, and particularly in the first month.

The relationship between birth weight and postnatal physical growth has been the concern of many workers who found positive correlations by retrospective analysis. $\sim \mathrm{Il} \cdot \mathrm{e}$,'Prospective studies have been done all too infrequently. For instance, two studies have shown that premature and small-for-date infants grow abnormally, $\cdot \mathrm{H}$ despite the provision of an adequate environment. The comprehensive study of the 1958 cohort of British infants disclosed that birth weight and gestational age were positively correlated with postnatal growth and development."

Little of this type of information is available from developing countries.
One study of Nigerian infants whose birth weights were below the tenth percentile for the region showed that they had a poorer weight gain than children with larger birth weight." A similar observation was recorded for Gambian newborns observed prospectively in their rural environment."

The relationship of birth weight and postnatal physical growth is important because psychomotor retardation, intellectual impairment, and lower survival are the sequelae of suboptimal fetal and postnatal growth and development.v-> ' Thus, birth weight is important as a predictor not only of survival, hut also of physical and intellectual development, particularly in preindustrial societies which have a very high incidence of low birth weight.

The importance of the present study lies in the fact that it is an eight-year prospective field observation of virtually the whole population of newborns in a typical Guatemalan village under natural conditions and without a variability imposed by intervention. We still need to learn more about the cause and pathogen- esis of low birth weight in developing countries in order to devise some type of control and achiev.e prevention. The role played by maternal nutrition cannot be denied, and measures to improve it must be undertaken. However, more emphasis should be given to assessing the contribution of certain pathologic processes in the mother that are susceptible to treatment or prevention. Infectious diseases are an example of such a process because they are a direct or a contributing cause of maternal malnutrition, as well as a cause of fetal growth retardation, abnormal development, and premature delivery. AIthqugh our knowledge of the factors responsible for the high rates of low birth weight in whole communities is still incomplete, application of what is already known can be an exciting challenge to those concerned with the solution of this problem.

This investigation was supported in part by Public Health Service' grant $\mathrm{N} 01 \cdot \mathrm{DH} \cdot 2-273 \mathrm{~T}$ from the National Institute of Child Health and Human Development; by the Pan American Health Organization; and by the Schoolof Public Health and Community Medicine of the University of Washington.

\section{Ref.rences}

1. Publu Health Aspects of Lou.' Birth Weight, 3rd report. Geneva, World Health Organization, 1961.

2. Bjerkedal T, BakketeiJ L, Lehmann EH: Percentiles of birth weights of single, live births at different gestational periods. Acta Paediatr \&and 62:449-457, 1973.

3. IntenatiMtal Comparison of Perinatal and In/ant Mortality: The United Sta.tes and Si;r West European Countries, publication 1000-series S-No. 6. National Center for Health Statistics, US Dept of

Health, Education and Welfare, 1967.

4. Jurado-Garcia E, Abarca A, Osorio C, at al: EI creeimiento intra-uterine: I. Evaluacion del pellO y la longitud eoTtJOrafetal en la Ciudad de Mexico: Analisls estadistim de 16,807 nacimientos consecutivos de prod cto unico vivo. Bol Med Hasp Infantil (MeztcO) 27:163-195,1970.

5. Shanna U: Intra-uterine growth retardation. Indian $\mathbf{J}$ Pediatr 35:454-459, 1968.

6. Salber EJ: The significance of birth weight as illustrated by a comparative study of South African racial groups. J TTfiP Pediatr 1:54-60, 1955

7. Mata LJ, Urrutia JJ, Garcia B: Effect of infection and diet on child growth: experience in a Guatemalan village, in Wolstenholme GEW, O'COnnor CM (eels): Nutriticm and Infection: Ciba FoundatiMI Stud1l Group No. 31. Boston, Little Brown \&: CO, 1967, pp 112-125.

8. Mata LJ, Urrutia JJ Lechtig A: Infection and nutrition of cltildren of a low socioeconomic rural community. Am $\mathbf{J}$ CTin Nut $r$ 24:249-259, 1971

9. Mata W, Urrutia JJ, Caceres A, et al: The biologic environment in a Guatemalan rural community. in Proceedinq" of the

Western HI'III. $\sim$ pl!rrrNutrition Conqres III. Mount Kisco, NY, Futura Publishing Co Inc. 1972 pp 257-264.

10. Mata W: Malnutrition and infection: Prospective study of the prohlem in a rural village of Guatemala, in Proceedings of the Tenth International Nutrition Congress, to be published.

11. Mata LJ, Kronmal RA, Urrutia JJ, et al: Antenatal events and postnatal growth and survival. in Proceedings of the We f('rn Hemisphere Nutrition. Congress $I V$, to be published.

12. Ell(lluacwn del Estado Nutricional, publication 9. Ensenando Nutricion series, Guatemala City, Institute of Nutrition of Central America and Panama, 1956

13. Neel JV, Chagnon NA: The demography oC two tribes of primitive, relatively unacculturated American Indians. hoc Natl Mad Sci USA 59:680-689, 1968 ,

14. Mata LJ, Urrutia JJ, Albertaz $\sim$ C, et al: Influence of recurrent inCectionson nutrition and growth of children in Guatemala. Am J Clin Nutr 25:1267-12751972.

15. Chase HC: Relationship of certain biologic and socioeconomicfactors to Cetal, infant and early childhood mortality: II. Father's occupation, infant's birth weight and mother's age, in Monthly Bulletin. Albany, NY, New York State Dept of
Health, 1962.

16. McKeown T, Gibson JR: Observations on all births $(23,970)$ in Birmingham 1947: IV. "Premature birth." $\mathrm{Br}$ Med J 2:513-517, 1951

17. A Sflldy of Infant MortaiifM From Linked Records, publication (HSM) 721055. US Dept of Health, Education and Welfare, 1972.

18. Behrman RE, Babson GS, Lessel R: Fetal and neonatal mortality in white middle class infants: Mortality risks b'y gestational age and weight. $A m J$ Dis Child 121:486-4891971.

19. Puffer RR, Serrano CV: Patterns IIf Mortality in Childhood, publication 262. Washington, DC, Pan American Health Organization, 1973.

20. Douglas JWB, Mogford C: The results of a national inquiry into the growth of premature children from birth to 4 years. Arch tx॥ Child 2i:436-445, 1953.

21. Lubchenco LO, Horner FA, Reed $\mathrm{LH}$, et al: Sequelae of premature birth: Evaluation of premature infants of low birth weights at 10 years of age. Am $\mathbf{J}$ Dis Child 106:101-115,1963.

22. Greenwald P, Funakawa H, Mitanui $\mathrm{S}$, et al: Influence of environmental factors on Cetal growth in man. Lancet 1:10261031,1967 .

23. Miller FJW, BillewiczWZ, Thomson AM: Growth from birth to adult life of 442 Newcastle upon Tyne children. Br J Pre» Soc Med 26:224-230, 1972

24. Babson SG: Growth of low-birth- 
weight infants. J Pediatr 77:11-18. 1970.

25.. Fit:l:hardinge PM. Steven ,EM: The small- f.or-.date.infant: I. Later i.rowtb patterns, $P \sim$ diatrir"49:6JH81, .1972.

26. Davie R. Butler N, Goldstein $\mathrm{H}$ From Birtb to Seren. William Clowes \& SCl(Ut Ltd, LcindOll,.1972,

ZT.,Morley' D 'Bickne 1 J. Woodland $\mathrm{M}$ : Faewr!,! jnftu nt:ing the gl'Owth and nutritional status of infants and young children i'I 'Il' Nbterial" vm4ltc'. 'T.r'(Irl $R$ SOCTmp
M"d If.!lrI 6 :164-199. 196M,

28. MCGreg'ur IA. Rahman AK. Thompson B, et al: The $\sim$ rnwth of young children' in a Gambian', illaKe. Tra $\mathrm{u}>\mathrm{i} R$ Soc Trop. Mfd Hyg 61!:!J.11-352, 196t!

29. Wi'ener G. Rider RV Oppel We.. et al: Correlates of low birth ,weight: Psycho10000 eastatus at 8 to 10 years of age. Pelli at» Re» 2:110-118. 196!!

30: Lubchenco LO. Deli"oria-Papli.do-' poulos.M. Searles D: Long-term \{olloW-up, st, $\mathrm{u} \sim$ ies of prematurely born infants: $\mathrm{n}$. Influence of birth weiJht and gestational age on 8e'IIJ.elae. J Pediatr 80:509-512. 1972.

31. Wright FH. Blough RR. Chamberlin A, et al: A controlled follow-up study of small prematures. born from 1952 through 1956: Am J Di CSU《 124:507-521, 1972.

' : II $\sim$ y JB:, S,rth w ight and subsequent 'p-hl'Ilical and intelledual developm t:. N E'!tgl J Mfd 289:973-974. 1973. 